\title{
RESEARCH
}

Open Access

\section{Malaria among foreign migrant workers in Savannakhet Province, Lao People's Democratic Republic}

Tiengkham Pongvongsa ${ }^{1,2}$, Daisuke Nonaka ${ }^{2,3^{*}}$, Moritoshi Iwagami ${ }^{2,4,5}$, Pheovaly Soundala ${ }^{2,5}$, Phonepadith Khattignavong ${ }^{2,5}$, Phonepadith Xangsayarath ${ }^{2,6}$, Futoshi Nishimoto ${ }^{7}$, Jun Kobayashi ${ }^{2,3}$, Bouasy Hongvanthon ${ }^{2,8}$, Paul T. Brey ${ }^{2,5}$ and Shigeyuki Kano ${ }^{2,4}$

\begin{abstract}
Background: Although mobile and migrant populations are considered an important group in malaria elimination settings, there is currently a lack of understanding about foreign migrant workers in the Lao People's Democratic Republic (Lao PDR). The present study aimed to document the migration characteristics, positive rate of malaria infection, and preventive and treatment-seeking behavior for malaria among foreign migrant workers in the malaria-endemic districts of Savannakhet province, Lao PDR.
\end{abstract}

Methods: A community-based survey was undertaken in four districts of Savannakhet province between February and June, 2015. Questionnaire-based interviews and blood examinations, including rapid diagnostic tests and PCR assays, were conducted with 391 migrant workers who were registered at local police departments.

Results: Most of the study participants were men (75.7\%) and Vietnamese (92.6\%). The median age (interquartile range) was 31 (25 to 41) years old. Most common occupation was factory worker (47.6\%), followed by trader/ shopkeeper (21.5\%) and plantation worker/farmer (16.4\%). The median length of stay (interquartile range) in the districts was 405 (183 to 1207) days. The majority of the participants (85.9\%) had not worked in a province other than the study province, nor had the majority (92.6\%) worked in a foreign country other than the Lao PDR. Although most of the participants (62.7\%) reportedly used a bed net daily, these nets were mostly conventional untreated ones. No one tested positive for malaria. However, $10.0 \%$ of the participants reported a malaria-like illness episode that had occurred in the Lao PDR. The most common measure taken for the episode was to visit a hospital/health center in the Lao PDR, followed by conducting self-medication alone. Forty-one participants reported an experience of working in the forest while living in the Lao PDR.

Conclusions: Foreign migrant workers who are registered at local police departments are unlikely to play a major role in maintaining local transmissions and spreading drug-resistant malaria in the study province. However, some of them were involved in forest-related activities, suggesting that these workers are potentially at risk of malaria. The Lao National Malaria Control Program should educate foreign migrant workers about the risk of malaria when living in Lao PDR.

Keywords: Malaria, Labor migration, International migration, Laos, Vietnam, Risk factor, Help-seeking behavior

\footnotetext{
* Correspondence: laodaisuke@hotmail.co.jp

${ }^{2}$ SATREPS Project for Parasitic Diseases, Vientiane Capital, Lao PDR

${ }^{3}$ Department of Global Health, School of Health Sciences, University of the

Ryukyus, 207 Uehara, Nishihara-cho, Okinawa 903-0215, Japan

Full list of author information is available at the end of the article
}

(C) The Author(s). 2019 Open Access This article is distributed under the terms of the Creative Commons Attribution 4.0 International License (http://creativecommons.org/licenses/by/4.0/), which permits unrestricted use, distribution, and reproduction in any medium, provided you give appropriate credit to the original author(s) and the source, provide a link to the Creative Commons license, and indicate if changes were made. The Creative Commons Public Domain Dedication waiver (http://creativecommons.org/publicdomain/zero/1.0/) applies to the data made available in this article, unless otherwise stated. 


\section{Background}

The burdens of malaria have decreased in the Lao People's Democratic Republic (Lao PDR) in recent years: estimated malaria cases dropped from 51,000 in 2010 to 27,390 in 2016 [1]. A current challenge to malaria control in the Lao PDR is the emergence of drug-resistant malaria [2]. In 2015, the countries in the Greater Mekong Sub-region (GMS) such as Cambodia, China (specifically Yunnan Province and Guangxi Zhuang Autonomous Region), Lao PDR, Myanmar, Thailand, and Vietnam adopted the malaria elimination strategy that was proposed by the World Health Organization because Plasmodium falciparum resistance to antimalarial medicines had reached alarming levels in certain areas of the GMS, and the only solution is to eliminate $P$. falciparum from the GMS. The GMS countries have been working to eliminate all species of human malaria by 2030 [3].

The Asian Highway and GMS economic corridors that cut through endemic areas in GMS countries including Lao PDR are contributing to the increased population movement between and within GMS countries [4]. In response to the recent rapid economic development in the Lao PDR, increasing numbers of migrant workers are entering the Lao PDR from Vietnam, China, Thailand, and Myanmar. For example, hydropower dam projects in Attapeau province involved an estimated 4000 to 5000 workers at the peak of the construction phase in 2012, the majority of whom were Vietnamese and Chinese [5].
There are estimated to be 54,000 foreign migrant workers in the Lao PDR in 2017 [6].

The National Malaria Control Program of the Lao PDR has paid special attention to migrant workers for a number of reasons. First, migrant workers are likely to be involved in spreading drug-resistant malaria from one area to another. Second, migrant workers are considered to be at high risk of contracting malaria. In a large outbreak that occurred in Attapeau province, migrants, both from other provinces in the Lao PDR and from neighboring countries, accounted for the majority of the reported cases $[2,5]$. Finally, foreign migrants are particularly likely to contribute to maintaining local transmissions as they may be less likely to seek treatment from a local healthcare service compared to those of Lao nationality $[5,7]$.

Among the 18 provinces of the Lao PDR, Savannakhet province is a major province to which Vietnamese emigrate [8]. As the largest province $\left(21,774 \mathrm{~km}^{2}\right)$ in the Lao PDR, it is bordered by Vietnam to the east and Thailand to the west. Approximately $90 \%$ of all malaria cases in the Lao PDR occur in the five southernmost provinces, of which Savannakhet is one [9]. Of the 15 districts in Savannakhet province, malaria is endemic in four districts: Thapangthong, Nong, Xepon, and Phin (Fig. 1).

There is currently a lack of understanding about foreign migrant workers in the Lao PDR in terms of

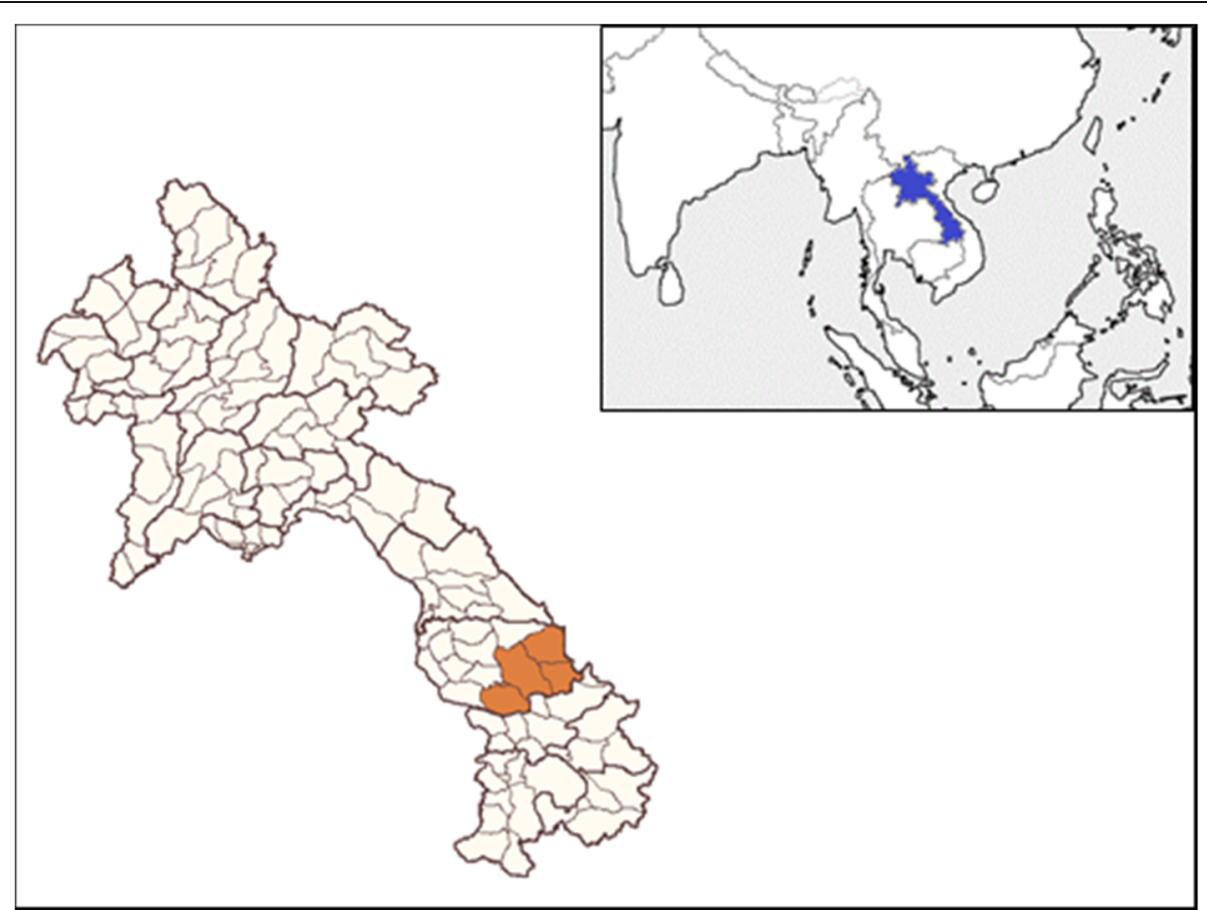

Fig. 1 Map of the Lao PDR and the study districts. The small map insert at the upper right shows the location of the Lao PDR highlighted in blue. The large map shows the location of the four study districts of Thapangthong, Nong, Xepon, and Phin highlighted in brown 
designing and implementing malaria control strategies to better target them. Therefore, the present study aimed to document the migration characteristics, positive rate of malaria infection, and preventive and treatment-seeking behavior for malaria among foreign migrant workers in the four malaria-endemic districts of Savannakhet province, Lao PDR.

\section{Methods}

\section{Study site and participants}

The present study was conducted in the four districts of Thapangthong, Nong, Xepon, and Phin in Savannakhet province, whose populations in 2015 were 40,584, $29,622,56,213$, and 65,085 , respectively [10]. Prior to field survey, the research team estimated the number of registered foreign migrant workers to be around 100 to 150 in each district, on the basis of the information from relevant authorities.

In each district, the research team visited the local police office, where local residents are registered, to collect information on the residences and workplaces of foreign migrant workers. Then, the team visited the residences and/ or workplaces of these workers with the help of the local authorities, including village heads. When an eligible foreign migrant worker was absent, multiple attempts were made to contact him/her.

The research team included in the present study all of the foreign migrant workers on whom information was provided by the local police office. Foreign migrant workers were excluded if they were aged less than 15 years old or refused to participate in the study. Out of a total of 520 registered foreign migrant workers (Thapangthong 100, Xepon 150, Nong 120, and Phin 150), 392 participated in the study (participation rate $75.4 \%$ ). The majority of eligible foreign migrant workers, who were not included, were absent mainly either because they were staying in Vietnam at the time of the visit or because they appeared to be no longer living in the study districts. Of the participants, only one participant who withdrew from an interview survey was excluded. Thus, the present study analyzed the data of 391 participants.

\section{Data collection}

A community-based survey was performed between February and June, 2015. The survey included a questionnaire-based interview with a blood examination of each study participant. The questionnaire was first developed in English and then was translated into Lao, Vietnamese, and Chinese languages. Whenever a participant was able to communicate in Lao language, Lao version questionnaire was used. Healthcare professionals including two fluent Vietnamese speakers, who belong to a Lao governmental institution, worked as surveyors. Prior to data collection, the surveyors were trained for a day on data collection procedures. The questionnaire included questions on migration characteristics, socio-demographic and economic characteristics, behavior for malaria prevention and treatment, general healthcare-seeking behavior, and forest activity. Most of the questions were presented with response options: For example, the response options for most of the questions on preventive behavior were "Everyday," "Often," "Sometimes," and "Never." Questions pertaining to general healthcare-seeking behavior and forest activity were added to the questionnaire during the data collection stage, meaning that these questions were not asked of participants $(n=77)$ in the first study district, i.e., Thapangthong district. The reason for adding the questions was that the research team realized the need for collecting information more comprehensively, as no participant was found to be positive by rapid diagnostic test and a few participants reported a malaria-like illness episode in the first district. The blood examination included a rapid diagnostic test (BinaxNOW ${ }^{\circ}$ Malaria test) and PCR assay. The PCR assays were performed as described elsewhere [11]. Rapid diagnostic tests were used to provide on-site diagnosis, whereas PCR assays were used to determine malaria infection as the gold standard: The limit of detection for rapid diagnostic tests is generally in the order of 100 parasites/ $\mu \mathrm{l}$, whereas lab-based PCR methods generally have limits of detection of $<5$ parasites/ $\mu \mathrm{l}$ [12].

\section{Statistical analysis}

Bivariate and multivariate analyses were carried out to examine factors associated with each participant's selfreported malaria-like illness episode that occurred in the Lao PDR. Factors examined in the analyses were age ( $\leq 29$ years, $30-39$ years, $40-49$ years, or $\geq 50$ years), gender (male or female), occupation (factory worker, trader/shopkeeper, plantation worker, farmer, construction worker, or wood cutter/forest worker), use of bed net (every day, often, sometimes, or never), and experience of forest activity (yes or no). The odds ratio (OR) and $95 \%$ confidence interval (CI) of the outcome (malaria-like illness episode) for each factor were estimated using a mixed-effect logistic regression analysis, with the district-level clustering being treated as a random effect. For the multivariate analysis, all of the factors were entered into the model. These analyses were performed using the STATA MP 12 software program (StataCorp LP, College Station, TX, USA).

\section{Results}

\section{Blood examination}

No participants tested positive for malaria either by rapid diagnostic test or by PCR assay. Therefore, the positive rate of malaria infection was $0 \%(0 / 391)$. 


\section{General characteristics}

Most of the participants $(75.7 \%)$ were men, with a median age of 31 years old (Table 1), and most (92.6\%) were Vietnamese, with the remaining participants being either Chinese or Thai. The most common occupation was sawmill factory worker (24.6\%), followed by trader/shopkeeper (21.5\%), industrial factory worker (18.4\%), plantation worker/farmer (16.4\%), and repairer (5.1\%). The location of the participants included both urban (i.e., township) and rural areas (i.e., forest fringe).

\section{Migration characteristics}

When migrating to the study district, most of the participants were accompanied either by a friend $(36.1 \%)$ or by a family member (33.2\%) (Table 2 ). At the time of the survey, the participants' median length of stay in the study district was 405 days (interquartile range, 183 to 1207 days). The majority of the participants (85.9\%) had not worked in a province other than the study province, nor had the majority (92.6\%) worked in a foreign country other than the Lao PDR.

Table 1 General characteristics of study participants

\begin{tabular}{|c|c|c|}
\hline Characteristics & Number $(n=391)$ & $\overline{\text { Percentage }}$ \\
\hline \multicolumn{3}{|l|}{ Gender } \\
\hline Male & 296 & 75.7 \\
\hline Female & 95 & 24.3 \\
\hline \multicolumn{3}{|l|}{ Age (years) } \\
\hline Median (interquartile range) & 31 (25 to 41$)$ & \\
\hline \multicolumn{3}{|l|}{ Nationality } \\
\hline Vietnamese & 362 & 92.6 \\
\hline Chinese & 23 & 5.9 \\
\hline Thai & 6 & 1.5 \\
\hline \multicolumn{3}{|l|}{ Occupation } \\
\hline Sawmill factory worker & 96 & 24.6 \\
\hline Trader/shopkeeper & 84 & 21.5 \\
\hline Industrial factory worker & 72 & 18.4 \\
\hline Plantation worker/farmer & 64 & 16.4 \\
\hline Repairer & 20 & 5.1 \\
\hline Furniture factory worker & 18 & 4.6 \\
\hline Construction worker & 11 & 2.8 \\
\hline Wood cutter & 8 & 2.0 \\
\hline Other & 18 & 4.6 \\
\hline \multicolumn{3}{|l|}{ Study site } \\
\hline Thapangthong district & 77 & 19.7 \\
\hline Xepon district & 104 & 26.6 \\
\hline Nong district & 108 & 27.6 \\
\hline Phin district & 102 & 26.1 \\
\hline
\end{tabular}

Table 2 Migration characteristics of the study participants

\begin{tabular}{llc}
\hline Characteristics and behavior & Number $(n=391)$ & Percentage \\
\hline Migration to the study site & 141 & 36.1 \\
With friend & 130 & 33.2 \\
With family member & 118 & 30.2 \\
Alone & 2 & 0.5 \\
With company staff & 405 (183 to 1207) \\
Length of stay in the study site & \\
in days, median (interquartile range) & & \\
Experience of working in a province other than the study province \\
Yes & $55^{\text {a }}$ & 14.1 \\
No & 336 & 85.9 \\
Unknown & 1 & 0.3 \\
Experience of working in a foreign country other than Lao PDR \\
Yes & $28^{\text {b }}$ & 7.2 \\
No & 362 & 92.6 \\
Unknown & 1 & 0.3 \\
\hline
\end{tabular}

${ }^{a}$ The provinces were Salavan, Champasack, Vientiane City, Attapeau, Bolikhamxay, Khammuan, and others

${ }^{\mathrm{b}}$ The foreign countries were Thailand, Cambodia, Malaysia, and others

\section{Malaria preventive behavior}

Although most of the participants (62.7\%) used a bed net daily, non-users (10.2\%) and infrequent users (7.2\%) also existed (Table 3). The use of mosquito repellent skin lotion was uncommon: $86.7 \%$ never used such lotions. Eleven participants (2.8\%) had taken an anti-malaria medicine for malaria prevention when living in the Lao PDR: three participants reportedly took quinine, and the remainder did not remember the name of the medicine. These 11 participants did not take the medicine frequently.

\section{Characteristics of bed nets}

Of the 345 bed nets that the participants used, most $(n=253,73.3 \%)$ were conventional non-treated nets (data not shown in tables). Only 49 (14.2\%) of the participants used an insecticide-treated net. The insecticidetreated status was unclear for the 43 (12.5\%) remaining bed nets. Over half of the bed nets used were obtained in Vietnam ( $n=195,56.5 \%)$, whereas fewer bed nets were obtained in the Lao PDR $(n=25,7.2 \%)$ and Thailand $(n=23,6.7 \%)$. The place of origin of $102(29.6 \%)$ bed nets was unclear.

\section{Treatment-seeking behavior for malaria-like illness}

Thirty-nine participants (10.0\%) reported a malaria-like illness episode that occurred while living in the Lao PDR (Table 4). The most common measure taken for the episode was to visit a hospital/health center in the Lao PDR ( $n=23,59.0 \%$ ), followed by conducting self-medication alone $(n=6,15.4 \%)$ and taking a rest alone $(n=6$, 
Table 3 Malaria preventive behavior of the study participants

\begin{tabular}{lll}
\hline Characteristics & Number $(n=391)$ & Percentage \\
\hline Frequency of bed net use & \\
Everyday & 245 & 62.7 \\
Often & 78 & 19.9 \\
Sometimes & 28 & 7.2 \\
Never & 40 & 10.2 \\
Frequency of mosquito repellent skin lotion use & \\
Everyday & 4 & 1.0 \\
Often & 10 & 2.6 \\
Sometimes & 31 & 7.9 \\
Never & 339 & 86.7 \\
Unknown & 7 & 1.8 \\
Experience of taking anti-malaria medicine for malaria prevention in \\
Lao PDR \\
Yes & $11^{\text {a }}$ & \\
No & 375 & 2.8 \\
Unknown & 5 & 95.9 \\
Frequency of taking the anti-malaria medicine $(n=11)$ \\
Everyday & 0 & 1.3 \\
Often & 0 & 0.0 \\
Sometimes & 4 & 0.0 \\
Rarely & 6 & 36.4 \\
Unknown & 1 & 54.5 \\
\hline
\end{tabular}

${ }^{a}$ Three people took quinine as the medicine, whereas the remaining 8 people did not remember the name of the medicine

15.4\%). Among the 24 participants who visited a hos$\mathrm{pital} /$ health center, nearly half $(n=11,45.8 \%)$ conducted self-medication prior to the visit.

The majority of the participants $(n=28,71.8 \%)$ who reported a malaria-like illness episode had not worked in a province other than the study province (data not shown in tables).

\section{General healthcare-seeking behavior}

Of the 314 participants from the Xepon, Nong, and Phin districts, the majority $(n=279,88.9 \%)$ reported that they had not experienced seeking healthcare service from Lao medical staff (Table 5). Among the participants who had sought healthcare, the major healthcare service they received was treatment $(n=24,80.0 \%)$. In response to the hypothetical question "If you get sick, then would you like to utilize a Lao hospital/health center?", $61.8 \%$ of the participants answered "Yes," whereas 18.2\% answered "No" and $18.5 \%$ answered "Not sure."

\section{Forest activity}

Of the 314 participants from Xepon, Nong, and Phin districts, 41 (13.1\%) reported an experience of working in the forest while living in the Lao PDR (data not
Table 4 Treatment-seeking behavior of the study participants for a self-reported malaria-like illness episode

\begin{tabular}{lcc}
\hline Characteristics & $\begin{array}{c}\text { Number } \\
(n=391)\end{array}$ & Percentage \\
\hline $\begin{array}{l}\text { Experience of suffering from malaria-like illness in their home countries } \\
\text { Yes }\end{array}$ & 18 & 4.6 \\
No & 370 & 94.6 \\
Unknown & 3 & 0.8 \\
Experience of suffering from malaria-like illness in Lao PDR & \\
Yes & 39 & 10.0 \\
No & 352 & 90.0 \\
Behavior of the study participants for the malaria-like illness & \\
episode that occurred in Lao PDR ( $n=39)$ & & \\
Visited a health center/hospital in Lao PDR & 23 & 59.0 \\
Visited a health center/hospital in Vietnam & 1 & 2.6 \\
Conducted self-medication alone & 6 & 15.4 \\
Took a rest alone & 6 & 15.4 \\
Unknown & 3 & 7.7 \\
Conducted self-medication prior to the visit to the health & \\
center/hospital in Lao PDR/Vietnam ( $n=24)$ & & \\
Yes & 11 & 45.8 \\
No & 13 & 54.2 \\
\hline
\end{tabular}

shown in tables). The objectives of the forest work were wood cutting $(n=12,29.3 \%)$, plantation building ( $n=11$, $26.8 \%)$, swidden $(n=9,22.0 \%)$, seeking forest products $(n=5,12.2 \%)$, and others $(n=4,9.8 \%)$.

\section{Factors associated with malaria-like illness episodes}

Bivariate analysis showed a statistically significant association between malaria-like illness episodes and age, occupation, and forest activity in the Lao PDR (Table 6). The participants aged 50 years or older were significantly more likely to have had a malaria-like illness episode compared to those aged 29 years or younger (OR 6.46, $95 \%$ CI 2.19 to 19.05 ). Additionally, construction workers/wood cutters were significantly more likely to have had a malaria-like illness episode compared to factory workers (OR 5.96, 95\% CI 1.08 to 32.79 ). The participants who were involved in forest-related activities while living in the Lao PDR were significantly more likely to have had a malaria-like illness episode compared to those who were not involved in such activities (OR 5.53, 95\% CI 2.31 to 13.25$)$.

Multivariate analysis confirmed the significant association of malaria-like illness episodes with age (OR 4.90, 95\% CI 1.54 to 15.54 ) and forest activity (OR 5.24, 95\% CI 1.91 to 14.34 ), whereas the association between malaria-like illness episodes and occupation (construction workers/wood cutters) became insignificant in the multivariate analysis (OR 4.81, 95\% CI 0.88 to 26.30 ). 
Table 5 General healthcare-seeking behavior of the study participants

\begin{tabular}{lcc}
\hline Characteristics & Number $(n=314)$ & Percentage \\
\hline Experience of seeking healthcare service from Lao medical staff \\
Yes & 30 & 9.6 \\
No & 279 & 88.9 \\
Unknown & 5 & 1.6 \\
Healthcare service he/she received $(n=30)$ & \\
Medical check-up & 1 & 3.3 \\
Treatment & 24 & 80.0 \\
Consultation & 0 & 0.0 \\
Obtained drug & 2 & 6.7 \\
Unknown & 3 & 10.0 \\
If you get sick, would you like to utilize a Lao health center/hospital? \\
Yes & 194 & 61.8 \\
No & 57 & 18.2 \\
Not sure & 58 & 18.5 \\
Unknown & 5 & 1.6 \\
\hline
\end{tabular}

\section{Discussion}

In the present study involving 391 foreign migrant workers from Thapangthong, Xepon, Nong, and Phin districts in 2015, no participants tested positive for malaria, even though a number of studies that were conducted with the general Laotian population in these districts between 2013 and 2015 reported substantial positive rates of Plasmodium infections. One study that was conducted with 891 villagers in 10 villages in Xepon district reported a positive rate of $6 \%$ [13], and a study conducted with 888 villagers in 18 villages in Thapangthong and Nong reported a positive rate of $20 \%$ [14]. Therefore, the study participants of the present study can be considered to be at low risk of malaria infection and registered foreign migrant workers in the study province might not be a high-risk group.

None of the participants in the present study were infected with malaria at the time of blood examination. A possible explanation for the absence of positive participants is that the present study did not include unregistered/illegal foreign migrant workers, of whom there are estimated to be 24,000 among the 54,000 foreign migrants in the Lao PDR [6]. These workers are more likely to have malaria infection as compared to registered/legal foreign migrant workers because they deliberately avoid contact with Lao governmental facilities. Another possible reason is that the majority of the study participants were not involved in logging, dam construction, or mining, which are thought to be high-risk occupations [9].

A further study is necessary that targets unregistered/ illegal foreign migrant workers in the Lao PDR. Sampling will be a challenge, however, because these workers are hard to reach. A study conducted in Thailand to explore knowledge, perception, and practices pertaining to malaria [15] included both registered and unregistered foreign migrant workers. That study used respondent-driven sampling, which is an extension of snowball sampling. It may be possible to gain access to unregistered/illegal foreign migrant workers in the Lao PDR if snowball sampling is applied.

Among the study participants, $62.7 \%$ used a bed net daily. This percentage is lower than those reported from studies conducted with the general Laotian population in the same districts: $82.7 \%$ in villages with high incidence and $82.3 \%$ in villages with low incidence of malaria in Xepon [16] and $76.8 \%$ in villages of Nong and Thapangthong districts [14].

In the present study, $10 \%$ of the participants reported a malaria-like illness episode that had occurred in the Lao PDR. Because $86 \%$ of the participants had no experience of working in a province other than the study province, they may have contracted malaria-like illness in the study province. Some of these malaria-like illness episodes could be due to malaria because such illness episodes were significantly associated with the involvement in forest-related activities. In the study province, involvement in forest-related activities is known to be a risk factor of malaria $[14,16]$.

Approximately $95 \%$ of the study participants had reportedly never experienced malaria in their mother countries. Thus, they may not have been aware of the risk of malaria while living in the Lao PDR. Foreign migrant workers who live in malaria-endemic districts in the Lao PDR should be educated about the risk of contracting malaria when working in the forest in the Lao PDR.

Approximately $60 \%$ of the participants used a Lao healthcare facility such as a health center or hospital for treatment of a self-reported malaria episode. This percentage could be reasonable because more than half of the participants had been living in the Lao PDR for over a year and thus might not have had a critical language barrier, which is known to be a major barrier for migrants for the use of the healthcare services of a host country [17-19]. Another possible reason is that the use of a public healthcare facility for malaria treatment is common among some Vietnamese. A study conducted with the general Vietnamese population in Quang Tri province, which borders the study province, showed that $90 \%$ of respondents used a public healthcare facility for treatment of a malaria episode [20].

The present study has some limitations. First, because the survey period did not coincide with the high transmission season (often between June and August) [21], the present study could underestimate the prevalence of 
Table 6 Factors associated with malaria episodes that occurred in Lao PDR among the study participants $(n=308)$

\begin{tabular}{|c|c|c|c|c|c|}
\hline \multirow[t]{2}{*}{ Variables } & \multirow[b]{2}{*}{ Malaria episode (\%) } & \multicolumn{2}{|c|}{ Bivariate analysis } & \multicolumn{2}{|c|}{ Multivariate analysis } \\
\hline & & Odds ratio & $95 \% \mathrm{Cl}^{\mathrm{a}}$ & Odds ratio & $95 \% \mathrm{Cl}^{\mathrm{a}}$ \\
\hline \multicolumn{6}{|l|}{ Gender } \\
\hline Female & 5.6 & 1.00 & Reference & 1.00 & Reference \\
\hline Male & 11.9 & 2.23 & $0.75-6.64$ & 1.53 & $0.42-5.61$ \\
\hline \multicolumn{6}{|l|}{ Age (years) } \\
\hline$\leq 29$ & 5.6 & 1.00 & Reference & 1.00 & Reference \\
\hline $30-39$ & 9.9 & 1.82 & $0.65-5.09$ & 1.32 & $0.44-3.96$ \\
\hline $40-49$ & 13.8 & 2.74 & $0.97-7.72$ & 2.01 & $0.62-6.46$ \\
\hline$\geq 50$ & 29.0 & 6.46 & $2.19-19.05$ & 4.90 & $1.54-15.54$ \\
\hline \multicolumn{6}{|l|}{ Occupation } \\
\hline Factory worker & 7.1 & 1.00 & Reference & 1.00 & Reference \\
\hline Trader/shopkeeper & 8.5 & 1.09 & $0.23-5.19$ & 2.06 & $0.50-8.46$ \\
\hline Plantation worker/farmer & 17.2 & 2.54 & $0.88-7.31$ & 1.29 & $0.44-3.83$ \\
\hline Construction worker/wood cutter & 33.3 & 5.96 & $1.08-32.79$ & 4.81 & $0.88-26.30$ \\
\hline Other & 11.5 & 1.56 & $0.32-7.54$ & 1.39 & $0.29-6.60$ \\
\hline \multicolumn{6}{|l|}{ Use of bed net } \\
\hline Every day/often & 11.1 & 1.00 & Reference & 1.00 & Reference \\
\hline Sometimes/never & 9.6 & 0.74 & $0.32-1.74$ & 0.76 & $0.30-1.92$ \\
\hline \multicolumn{6}{|l|}{ Forest activity in Lao PDR } \\
\hline No & 6.7 & 1.00 & Reference & 1.00 & Reference \\
\hline Yes & 26.8 & 5.53 & $2.31-13.25$ & 5.24 & $1.91-14.34$ \\
\hline
\end{tabular}

malaria infection. Second, the participation rate was $75.4 \%$, suggesting that there is a possibility of selection bias. Because only limited information was available on the eligible workers who were not included, the present study was unable to estimate the impacts of this bias on the study findings. However, the impacts might not be large, as the major reason for the non-participation was not the refusal but the absence. Additionally, the survey widely covered the location of participants. Finally, apart from blood examinations, the data collection relied on the self-report of participants. Therefore, some malaria-like illness episodes might not be due to malaria and the information on behavioral and migration characteristics might not be accurate. Despite these limitations, the present study is, to be the best knowledge, the first study that reported the prevalence of malaria infection, migration characteristics, and preventive and treatment behaviors among foreign migrant workers in Lao PDR.

\section{Conclusions}

The foreign migrant workers who are registered at local police departments are unlikely to play a major role in maintaining local transmissions and spreading drug-resistant malaria in the study province. However, some of them were involved in forest-related activities that were significantly associated with malaria-like illness episodes, suggesting that they are potentially at risk of malaria. For treatment of these episodes, the majority of the study participants used a local Lao healthcare facility. The use of a bed net was common, although their nets were mostly conventional untreated ones. Because $94.6 \%$ of the participants had not experienced malaria in their mother countries, they may not be very aware of the risk of malaria while living in the Lao PDR. Therefore, the Lao National Malaria Control Program should educate foreign migrant workers about the risk of acquiring malaria in the Lao PDR. Because the present study included only registered foreign migrant workers, a further study that targets unregistered foreign migrant workers is also warranted.

\section{Acknowledgements}

The authors sincerely thank the study participants and the field surveyors for their contributions to this study.

Funding

This study was partly supported by a JICA/AMED SATREPS project for the "Development of innovative research techniques in genetic epidemiology of malaria and other parasitic diseases in the Lao PDR for containing their expanding endemicity" and the Grant for National Center for Global Health and Medicine (28-4). 


\section{Availability of data and materials}

The datasets used and/or analyzed during the current study are available from the corresponding author on reasonable request.

\section{Authors' contributions}

TP and DN were the principal investigators and drafted the manuscript with the help of MI and SK. MI, PS, PK, PX, and FN contributed to the data collection. $\mathrm{MI}, \mathrm{PS}$, and PK contributed to the laboratory procedures. MI, JK, and SK contributed to the conception of the study. MI, BH, PTB, and SK contributed to the data analysis and reviewed the manuscript. All authors read and approved the final manuscript.

\section{Ethics approval and consent to participate}

The protocol for the present study was approved by the National Ethics Committee for Health Research, Ministry of Health, Lao PDR (No. 003/2015). Prior to the survey, surveyors explained to the participants the details of this study, such as its purpose, that participation was voluntary, the information that would be collected, and how data would be kept and managed. Written informed consent was obtained from each respondent.

\section{Consent for publication}

Not applicable.

\section{Competing interests}

The authors declare that they have no competing interests.

\section{Publisher's Note}

Springer Nature remains neutral with regard to jurisdictional claims in published maps and institutional affiliations.

\section{Author details}

${ }^{1}$ Savannakhet Provincial Health Department, Phonsavangnuea village, Kaysone-Phomvihan district, Savannakhet, Lao PDR. ${ }^{2}$ SATREPS Project for Parasitic Diseases, Vientiane Capital, Lao PDR. ${ }^{3}$ Department of Global Health, School of Health Sciences, University of the Ryukyus, 207 Uehara, Nishihara-cho, Okinawa 903-0215, Japan. ${ }^{4}$ Department of Tropical Medicine and Malaria, Research Institute, National Center for Global Health and Medicine, 1-21-1 Toyama, Shinjuku-ku, Tokyo 162-8655, Japan. ${ }^{5}$ Institut Pasteur du Laos, Ministry of Health, Sisattanak district, Vientiane Capital, Lao PDR. ${ }^{6}$ National Center for Laboratory and Epidemiology, Ministry of Health, Sisattanak district, Vientiane Capital, Lao PDR. ${ }^{7}$ Graduate School of International Health Development, Nagasaki University, 1-12-4 Sakamoto, Nagasaki-shi, Nagasaki 852-8523, Japan. ${ }^{8}$ Center of Malariology, Parasitology and Entomology, Ministry of Health, Sisattanak district, Vientiane Capital, Lao PDR.

Received: 22 October 2018 Accepted: 16 January 2019

Published online: 25 January 2019

\section{References}

1. WHO, UNICEF. The world malaria report, vol. 2017. Geneva: World Health Organization; 2017.

2. Ministry of Health: Lao People's Democratic Republic. National strategy for malaria control and elimination 2016-2030. Lao People's Democratic Republic: Ministry of Health; 2016.

3. WHO. Strategy for malaria elimination in the Greater Mekong Subregion: 2015-2030. Manila: World Health Organization Regional Office for the Western Pacific; 2015.

4. Gopinath D. Development projects, migration and malaria in the GMS Biregional Meeting on Healthy Borders in the GMS. Bangkok; 2013. http://www.searo.who.int/thailand/news/dev_projects_migration_malaria_ gms_dr_deyer.pdf. Accessed 11 Jan 2019

5. Kounnavong S, Gopinath D, Hongvanthong B, Khamkong C, Sichanthongthip O. Malaria elimination in Lao PDR: the challenges associated with population mobility. Infect Dis Poverty. 2017;6:81.

6. ASEAN Legal Information Portal. Savannakhet registers foreign workers. 2017. https://www.aseanlip.com/laos/employment/news/savannakhetregisters-foreign-workers/AL20548. Accessed 16 May 2018.

7. Suphanchaimat R, Kantamaturapoj K, Putthasri W, Prakongsai P. Challenges in the provision of healthcare services for migrants: a systematic review through providers' lens. BMC Health Serv Res. 2015;15:390.
8. Migration in the Greater Mekong Subregion resource book (Fourth edition) In-depth study: Border economic zones and migration. Chiang Mai: Mekong Migration Network (MMN) and Asian Migrant Centre (AMC); 2013.

9. Ministry of Health: Lao People's Democratic Republic. National strategy for malaria control and pre-elimination 2011-2015. Lao People's Democratic Republic: Ministry of Health; 2010.

10. Lao Statistics Bureau. Results of population and housing census 2015. Lao People's Democratic Republic: Ministry of Planning and Investment; 2015.

11. Komaki-Yasuda K, Vincent JP, Nakatsu M, Kato Y, Ohmagari N, Kano S. A novel PCR-based system for the detection of four species of human malaria parasites and Plasmodium knowlesi. PLoS One. 2018;13:e0191886.

12. WHO Evidence review group on malaria diagnosis in low transmission settings: malaria policy advisory committee meeting (session 10) report. Geneva: World Health Organization; 2014.

13. Pongvongsa $T$, Nonaka $D$, Iwagami M, Nakatsu M, Phongmany $P$, Nishimoto $F$, et al. Household clustering of asymptomatic malaria infections in Xepon district, Savannakhet province, Lao PDR. Malar J. 2016;15:508.

14. Phommasone K, Adhikari B, Henriques G, Pongvongsa T, Phongmany P, von Seidlein $L$, et al. Asymptomatic Plasmodium infections in 18 villages of southern Savannakhet Province, Lao PDR (Laos). Malar J. 2016;15:296.

15. Khamsiriwatchara A, Wangroongsarb P, Thwing J, Eliades J, Satimai W,

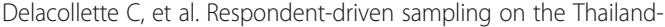
Cambodia border. I. Can malaria cases be contained in mobile migrant workers? Malar J. 2011;10:120.

16. Inthavong N, Nonaka D, Kounnavong S, Iwagami M, Phommala S, Kobayash J, et al. Individual and household factors associated with incidences of village malaria in Xepon district, Savannakhet province, Lao PDR. Trop Med Health. 2017:45:36.

17. Hunter-Adams J, Rother HA. A qualitative study of language barriers between South African health care providers and cross-border migrants. BMC Health Serv Res 2017;17:97.

18. Terry D, Ali M, Lê Q. Asian migrants' lived experience and acculturation to Western health care in rural Tasmania. Aust J Rural Health. 2011;19:318-23.

19. De Vito E, de Waure C, Specchia ML, Parente P, Azzolini E, Frisicale EM, et al. Are undocumented migrants' entitlements and barriers to healthcare a public health challenge for the European Union? Public Health Rev. 2016:37:13.

20. Pongvongsa $T$, Ha H, Thanh L, Marchand RP, Nonaka D, Tojo B, et al. Joint malaria surveys lead towards improved cross-border cooperation between Savannakhet province, Laos and Quang Tri province, Vietnam. Malar J. 2012;11:262.

21. Simmalavong N, Phommixay S, Kongmanivong P, Sichanthongthip O, Hongvangthong B, Gopinath D, et al. Expanding malaria diagnosis and treatment in Lao PDR: lessons learned from a public-private mix initiative. Malar J. 2017;16:460

Ready to submit your research? Choose BMC and benefit from:

- fast, convenient online submission

- thorough peer review by experienced researchers in your field

- rapid publication on acceptance

- support for research data, including large and complex data types

- gold Open Access which fosters wider collaboration and increased citations

- maximum visibility for your research: over $100 \mathrm{M}$ website views per year

At BMC, research is always in progress.

Learn more biomedcentral.com/submission 